\title{
Relationships of Disability, Health Management and Psychosocial Conditions to Cause-Specific Mortality Among a Community-Residing Elderly People
}

\author{
Noriyuki Nakanishi, Kozo Tatara, Masahisa Nishina, Kazue Nakajima, Hiromi Naramura, and \\ Hideo Yoneda
}

\begin{abstract}
To examine the factors associated with cause-specific mortality, a cohort of 1,405 randomly selected elderly people aged 65 years and over living in Settsu, Osaka Prefecture, was followed up for 54 months. Multivariate analysis using Cox proportional hazards model identified male sex, age, disability, medical treatment, and no participation in social activities as independent factors for overall mortality. Use of health checks and daily health enhancing practices showed an independent negative association with overall mortality. As for cause-specific mortality, male sex was a constant factor for the three major causes of death: cancer, heart disease and stroke. Advanced age and no participation in social activities showed a close association with heart disease mortality, while disability and medical treatment were independent factors for death caused by stroke and cancer, respectively. Use of health checks and daily health enhancing practices exhibited a strong negative association with all three major causes of death. The same tendencies were seen after those who reported undergoing medical treatment for the index diseases of heart disease and stroke at entry were excluded. These results suggest that predictive factors for mortality vary for specific causes of death, but that health promoting measures contribute to a reduction in mortality related to three major causes of death, thus resulting in a decrease in overall mortality among the elderly. J Epidemiol, $1998 ; 8: 195-202$.
\end{abstract}

mortality, cause-specific, elderly, correlated factors, prospective study

Previous epidemiological studies ${ }^{1-8)}$ have already demonstrated both theoretical bases and empirical evidence for causal links existing between certain indicators and mortality in elderly people. Age, male sex, self-rated health, degree of disability, satisfaction with life, social support, and sociability appear to be reliable predictive factors for overall mortality. However, a recent study from the National Mortality Follow-back Survey in the United States ${ }^{9}$ ) has shown that specific quality of life measurements in terms of functional status, mental awareness, and time spent in institutions differed in the year before death among those with specific causes of death, so that the predictors identified as risk factors for mortality could be expected to vary for specific causes of death. Identifying the factors potentially associated with cause-specific mortality could thus assist in the development of intervention programs designed to reduce the risk of all causes as well as cause-specific mortality in a high-risk population.

The present study was designed to evaluate demographic variables, disability, history of health management, and psychosocial conditions for predicting cause-specific mortality during a 54-month follow-up of a community-residing elderly Japanese population.

\section{MATERIALS AND METHODS}

\section{Subjects and baseline data}

On October 11992 when this study began, the city of Settsu had a total population of 87,293 , of whom $6,674(7.6 \%)$ were aged 65 years and older. Settsu is located on the right side of the lower reaches of the Yodo River, which runs in the northern part of the Osaka Plains. It is adjacent to Osaka City which is the principal city in Osaka Prefecture. The city area is flat on the whole and covers $15.71 \mathrm{~km}^{2}$. The climate is mild and the average annual temperature is $16^{\circ} \mathrm{C}$. Before the $1950^{\prime}$ 's, Settsu was a quiet rural city, but under the influence of the rapid economic growth which began in 1960's, many factories, ware-

Received February 25, 1998 ; accepted April 16, 1998.

Address for correspondence : Noriyuki Nakanishi, Department of Public Health Osaka University Medical School 2-2 Yamada-oka, Suita-shi, Osaka 565-0871, Japan. 
houses and stores have been established in the city and Settsu has been developing as a residential and industrial city. Highways for regional land transportation which run in all directions through the city make it the hub of transport in North Osaka. The percentage of those aged 65 years and older in Settsu was substantially lower than that of the total Japanese population (12.0\% in 1990), but is estimated to reach $21.9 \%$ in 2020.

A randomly selected sample of 1,491 people (22.3\%) aged 65 years and older from the computerized sex-age register, including 21 people in a nursing home, were visited at home and interviewed with the aid of a questionnaire. The interviews were conducted by well-trained district welfare commissioners between 1 and 26 October, 1992. Five people in the sample were found to have died, and 13 people had moved from Settsu, leaving 1,473 people to be contacted; responses were obtained from 1,405 people, a response rate of $95.4 \%$. Reasons for non-response were: absence ( 15 people); hospitalization (25 people); placement in an institution (21 people); and refusal to participate (7 people). Thus, institutionalized people were not included in this study.

The questionnaire included items related to the following aspects and has been detailed elsewhere ${ }^{10,11)}:$ (1) history of health management; (2) psychosocial conditions; and (3) health status as indicated by disability scores. For health management, we inquired into the history of day-to-day health enhancing practices related to diet and exercise, attendance at regular health checks since their youth (mainly at the work place) and at health checks by Settsu City under the Law for the Health and Medical Services for the Elderly, as well as current medical treatment. As for medical treatment, the subjects were asked to indicate which, if any, of the following diseases they had: hypertension, hyperlipidemia, heart disease, stroke, respiratory disease, digestive disease, diabetes mellitus, liver disease, pancreatic disease, renal disease, arthritis/lumbago, diseases of eye, ear and nose, senility, trauma/fracture, thyroid disease or other. Subjects were not asked about cancer, because in quite a few cases in Japan physicians notify their patients of a diagnosis of cancer. To assess psychosocial conditions, our questionnaire asked about elderly persons' involvement in their social network and in activities considered as particularly meaningful. The question asked in the questionnaire was 'Do you have Ikigai?' which could be translated directly as 'Do you have anything to live for?' It refers to particular aspects of one's life which make it meaningful or worth living.

For measuring disability, we adopted the concepts and methods developed by the Social Survey Division of the Office of Population Censuses (OPCS) ${ }^{12}$. These questionnaires are used to measure ten main areas or types of disability: degrees of locomotion, reaching and stretching, dexterity, seeing, hearing, personal care, continence, communication, behavior and intellectual functioning. Each type of disability is scored on a scale from 0 , which represents no disability, up to a maximum which differs for each item, the highest number corresponding to the most severe grade of disability. Because multiple disabilities are frequent, the OPCS survey developed an overall severity score based on the following formula using the scores for the three worst disability scores for each person: worst +0.4 (second worst) +0.3 (third worst). In our study, we also adopted this method to arrive at an 'overall disability score'. The scores were grouped into three categories for analysis: no disability (overall severity score of 0 ) or minor (0.5-4.95); appreciable disability (5-12.95); and severe disability (13 and over).

\section{Follow-up survey}

The survey population's status as of the end of March 1997 was determined from their resident registration cards and death certificates in order to verify their eligibility and outcomes. Of the 1,405 subjects enrolled in this study, the follow-up could be completed for only 1,306 (234 deceased and 1,072 alive) because 99 had moved from Settsu by the time of the followup.

Primary causes of death were coded according to the Ninth Revision of the International Classification of Diseases (ICD9) ${ }^{13)}$. For the present study, mortality due to cancer (ICD-9 Code No. 140-208), stroke (ICD-9 Code No. 430-438), and heart disease (ICD-9 Code No. 390-429) was analyzed.

\section{Statistical methods}

The survival times were calculated by using the date of enrollment and the date of death or the date of follow-up (end of March 1997), or the date of last registration. Those who had moved from Settsu during the follow-up period have censored survival times as do those members of the cohort who were living in Settsu at the end of the follow-up and who were still alive.

Cox proportional hazards model was used for univariate and multivariate modeling. When cause-specific mortality was examined, death from other than the disease being considered was treated as censoring. For these analyses, sex, undergoing medical treatment, participation in social activities, and life worth living (Ikigai) were used in a dichotomized format. Age, disability, use of health checks, and use of daily health enhancing practices were grouped into three sub-classes, and hazard ratio (HR) estimates in terms of the reference level of each sub-class were calculated by creating the two following dummy variables for each variable: $\mathrm{x} 1=0, \mathrm{x} 2=0$ for the reference level; $x 1=1, x 2=0$ for the second level; and $x 1=0, x 2=1$ for the third level. A hazard ratio of 1 indicates that there is no difference between the subgroups: a hazard ratio $>1(<1)$ indicates that a person in the designated "risk" subgroups is more (less) likely to die than a person in the designated baseline subgroup.

Data analysis was performed with the SPSS/PC statistical 
package (Marija J. Norusis/ SPSS Inc., Chicago, IL, USA). All reported p-values are two-tailed and a p-value of less than 0.05 was considered significant.

\section{RESULTS}

Distribution of the variables included in the analysis is shown in Table 1 . Of 234 total deaths, the leading cause was cancer ( 66 deaths, $28.2 \%$ ), followed by heart disease ( 46 deaths, $19.7 \%$ ) and stroke (32 deaths, $13.7 \%$ ); these three diseases comprised $61.5 \%$ of all deaths. The fourth leading cause was senility (ICD-9 Code No. 780-799; 31 deaths, 13.2\%), and respiratory disease (ICD-9 Code No. 460-519; 30 deaths, $12.8 \%$ ) ranked fifth. The ranking of the three major causes of death and their percentage were the same for the total population aged 65 years and over in Settsu during the observation period. According to responses at entry, 192 subjects (13.7\%) were under treatment for heart disease and $52(3.7 \%)$ for stroke. Ten (21.7\%) of the 46 who died from heart disease had reported undergoing medical treatment for heart disease, and among those who died of stroke, eight $(25.0 \%)$ had reported being treated for stroke.

Table 2 shows univariate HRs for overall and cause-specific mortalities by selected variables. Factors showing a statistically significant positive relationship with overall mortality were male sex, advanced age, greater disability, undergoing medical treatment, no participation in social activities, and lack of a sense that life is worth living (no Ikigai). The unadjusted HRs were 1.64 [95\% confidence interval (CI): 1.27-2.12] for male sex, 1.67 (95\% CI: 1.19-2.34) for medical treatment, 2.96 (95\% CI: 2.15-4.07) for no participation in social activities, and 2.45 (95\% CI: 1.86-3.23) for no meaningful life (no Ikigai). Compared with the age group of 65 to 74 years, the unadjusted HRs for the age groups of 75 to 84 years and 85

Table 1. Distribution of vital status and characteristics at baseline included in analysis.

\begin{tabular}{llr}
\hline Variable & Subclass & $\%, \mathrm{n}=1405$ \\
\hline Vital status, March 1997: Deceased & Overall & 16.7 \\
& Cancer & 4.7 \\
& Heart disease & 3.3 \\
& Stroke & 2.3 \\
Sex & Female & 59.9 \\
& Male & 40.1 \\
Age (years) & & \\
& $65-74$ & 61.7 \\
& $75-84$ & 31.9 \\
Disability * & $85+$ & 6.4 \\
& & \\
& No/Minor & 79.5 \\
Medical treatment & Appreciable & 14.7 \\
& Severe & 5.8 \\
Health checks & No & 25.0 \\
& Yes & 75.0 \\
& & 24.6 \\
Daily health enhancing practices & Not used & 32.5 \\
& Start at 60+ years & 42.8 \\
& Ntart at $<60$ years & 65.3 \\
Participation in social activities & No health practices & 15.3 \\
& Start at 60+ years & 19.4 \\
& Start at <60 years & 40.1 \\
& Yes & 59.9 \\
& No & 82.3 \\
& & 17.7 \\
\hline
\end{tabular}

* Complete data for measuring an overall severity score were available for 1,378 subjects. 
Table 2. Univariate hazard ratios * for overall and cause-specific mortalities.

\begin{tabular}{|c|c|c|c|c|c|c|c|c|c|c|c|c|c|c|}
\hline \multirow{2}{*}{ Variable } & \multirow{2}{*}{ Subclass } & \multicolumn{3}{|c|}{ Overall } & \multicolumn{4}{|c|}{ Cancer } & \multicolumn{3}{|c|}{ Heart disease } & \multicolumn{3}{|c|}{ Stroke } \\
\hline & & HR & $95 \% \mathrm{CI}$ & p value & $\mathrm{HR}$ & $95 \%$ & & $p$ value & HR & $95 \% \mathrm{CI} p$ & $p$ value & $\mathrm{HR}$ & $95 \% \mathrm{CI}$ & $p$ value \\
\hline \multirow[t]{2}{*}{ Sex } & Female & 1.00 & & & 1.00 & & & & 1.00 & & & 1.00 & & \\
\hline & Male & 1.641 .2 & $27-2.1$ & $2<0.001$ & 2.001 .2 & $23-$ & 3.25 & 0.005 & 1.540 .8 & $87-2.75$ & 0.141 & $\begin{array}{ll}1.55 & 0.7\end{array}$ & $77 \cdot 3.10$ & 0.16 \\
\hline \multirow[t]{3}{*}{ Age (years) } & $65-74$ & 1.00 & & & 1.00 & & & & 1.00 & & & 1.00 & & \\
\hline & $75-84$ & 2.301 .7 & $72-3.0$ & $37<0.001$ & 1.801 .1 & $10-$ & 2.97 & 0.020 & 1.640 .8 & $86-3.10$ & 0.132 & 2.010 .9 & $93-4.34$ & 0.075 \\
\hline & $85+$ & 8.646 .1 & $10-12.2$ & $25<0.001$ & 1.850 .6 & $65-$ & 5.23 & 0.247 & 5.192 .2 & $29-11.76$ & $5<0.001$ & 6.282 .3 & $38-16.60$ & $<0.001$ \\
\hline \multirow[t]{3}{*}{ Disability } & No/Minor & 1.00 & & & 1.00 & & & & 1.00 & & & 1.00 & & \\
\hline & Appreciable & 2.611 .9 & $00-3.5$ & $38<0.001$ & 0.990 .4 & $47-$ & 2.09 & 0.973 & 1.760 .8 & $84-3.72$ & 0.136 & 5.862 .4 & $44-14.07$ & $<0.001$ \\
\hline & Severe & 7.335 .2 & $21-10.3$ & $32<0.001$ & 3.061 .3 & $38-$ & 6.77 & 0.006 & 3.871 .6 & $61-9.33$ & 0.003 & 19.658 .1 & $16-47.32$ & $<0.001$ \\
\hline \multirow[t]{2}{*}{ Medical treatment } & No & 1.00 & & & 1.00 & & & & 1.00 & & & 1.00 & & \\
\hline & Yes & 1.671 .1 & $19-2.3$ & $34 \quad 0.003$ & 1.930 .9 & $99-$ & 3.78 & 0.055 & 1.630 .7 & $76 \cdot 3.49$ & $9 \quad 0.209$ & 1.030 .4 & $46-2.29$ & 0.947 \\
\hline \multirow[t]{3}{*}{ Health checks } & Not used & 1.00 & & & 1.00 & & & & 1.00 & & & 1.00 & & \\
\hline & Start at $60+$ years & 0.490 .3 & $36-0.6$ & $36<0.001$ & 0.440 .2 & $24-$ & 0.80 & 0.007 & 0.420 .2 & $21-0.84$ & $4 \quad 0.014$ & 0.500 .2 & $23-1.08$ & 0.078 \\
\hline & Start at $<60$ years & 0.280 .2 & $1-0.3$ & $9<0.001$ & 0.370 .2 & $21-$ & 0.66 & $<0.001$ & 0.280 .1 & $14-0.58$ & $8<0.001$ & 0.200 .08 & $88-0.51$ & $<0.001$ \\
\hline \multirow{3}{*}{$\begin{array}{l}\text { Daily health } \\
\text { enhancing practices }\end{array}$} & No health practices & 1.00 & & & 1.00 & & & & 1.00 & & & 1.00 & & \\
\hline & Start at $60+$ years & 0.630 .4 & $2-0.9$ & $95 \quad 0.027$ & 0.510 .2 & $22-$ & 1.20 & 0.123 & 0.210 .0 & $05-0.87$ & 0.031 & 0.630 .22 & $22-1.79$ & 0.382 \\
\hline & Start at $<60$ years & 0.490 .3 & $3-0.7$ & $73<0.001$ & 0.690 .3 & $36-$ & 1.33 & 0.272 & 0.310 .1 & $11-0.88$ & 0.028 & 0.120 .02 & $12-0.85$ & 0.035 \\
\hline \multirow{2}{*}{$\begin{array}{l}\text { Participation } \\
\text { in social activities }\end{array}$} & Yes & 1.00 & & & 1.00 & & & & 1.00 & & & 1.00 & & \\
\hline & No & 2.962 .1 & $5-4.0$ & $7>0.001$ & 1.410 .8 & $85-$ & 2.33 & 0.187 & 4.081 .8 & $83-9.13$ & $<0.001$ & 5.131 .80 & $30-14.61$ & 0.002 \\
\hline \multicolumn{2}{|c|}{ Life worth living (Ikigai) Yes } & \multicolumn{3}{|c|}{1.00} & \multicolumn{4}{|c|}{1.00} & \multicolumn{3}{|c|}{1.00} & \multicolumn{3}{|c|}{1.00} \\
\hline & № & 2.451 .8 & $6-3.2$ & $23<0.001$ & 1.450 .8 & $30-$ & 2.62 & 0.218 & 2.531 .3 & $36-4.68$ & 0.003 & 4.052 .01 & $1-8.41$ & $<0.001$ \\
\hline
\end{tabular}

* HR: hazard ratio; CI: confidence interval.

years or more increased by a factor of 2.30 (95\% CI: 1.72 3.07) and 8.64 (95\% CI: 6.10-12.25), respectively. The unadjusted HRs for appreciable and severe disabilities, compared with no/ minor disability, were, respectively, 2.61 (95\% CI: 1.90-3.58) and 7.33 (95\% CI: 5.21-10.32) times higher. On the other hand, both use of health checks and daily health enhancing practices showed statistically negative significant associations with mortality. Compared with no use of health checks, the unadjusted HRs for 'start at 60 years and older' and 'start at less than 60 years' were 0.49 (95\% CI: 0.36-0.66) and 0.28 (95\% CI: $0.21-0.39$ ), respectively. Relative to no daily health enhancing practices, the unadjusted HRs for 'start at 60 years and older' and 'start at less than 60 years' were $0.63(95 \% \mathrm{CI}$ : $0.42-0.95$ ) and 0.49 (95\% CI: $0.33-0.73$ ), respectively.

As for the risk ratios for cause-specific mortality, male sex showed a statistically significant unadjusted HR for cancer mortality. Unadjusted HRs for the age group of 85 years or more, no participation in social activities, and no meaningful life (no Ikigai) were greater for death from heart disease and stroke than for death from cancer, and all these variables reached statistical significance. Unadjusted HR for severe disability was significant for all three causes of death, and that for stroke mortality showed the highest unadjusted HR of 19.65 (95\% CI: 8.16-47.32). Unadjusted HRs for use of health checks and daily health enhancing practices tended to decrease with earlier use of these preventive health care measures as shown in overall mortality, and this tendency was more pronounced for the use of health checks. Medical treatment achieved marginal statistical significance for cancer mortality (HR: 1.93 , 95\% CI: 0.99-3.78, $\mathrm{p}=0.055$ ).

To determine if any of the risk factors were independently related to overall and cause-specific mortalities, the risk factors shown in Table 2 were included in a multivariate model in which factors independently associated with overall and causespecific mortalities were identified through mutual adjustment. Male sex, advanced age, greater disability, undergoing medical treatment, and no participation in social activities remained as statistically significant factors associated with overall mortality. The adjusted HRs were 2.28 (95\% CI: 1.74-2.98) for male sex, 1.47 (95\% CI: 1.03-2.12) for medical treatment, and 1.76 
(95\% CI: 1.22-2.53) for no participation in social activities. Compared with the age group of 65 to 74 years, the adjusted HRs for the age groups of 75 to 84 years and 85 years or more were 1.69 (95\% CI: 1.24-2.31) and 4.35 (95\% CI: 2.91-6.49), respectively. The adjusted HRs for appreciable and severe disabilities, compared with no/ minor disability, were, respectively, 1.43 (95\% CI: 1.02-2.02) and 2.61 (95\% CI: 1.75-3.91). Furthermore, relative to no use of health checks, the adjusted HRs for 'start at 60 years and older' and 'start at less than 60 years' were 0.65 (95\% CI: 0.47-0.90) and 0.49 (95\% CI: 0.340.70 ), respectively. Compared with no daily health enhancing practices, the adjusted HR for 'start at less than 60 years' was 0.65 (95\% CI: $0.43-0.99$ ).

As for cause-specific mortality, the adjusted HR for male sex maintained its statistical significance for all three causes of death. Age of 85 years or more and no participation in social activities were significant factors for mortality from heart disease, and these figures were 2.89 (95\% CI: 1.16-7.19) and 2.80 (95\% CI: 1.17-6.72), respectively. The adjusted HRs for appreciable and severe disabilities, 4.12 (95\% CI: $1.59-10.70)$ and
9.61 (95\% CI: 3.30-28.01), respectively, were significant for stroke mortality. Medical treatment showed a significant adjusted HR of 2.60 (95\% CI: 1.22-5.53) for cancer mortality. The adjusted HRs for 'start at 60 years and older' and 'start at less than 60 years' in case of the use of health checks and daily health enhancing practices remained at less than 1.0 , and significant adjusted HRs were seen for 'start at 60 years and older' of health checks for cancer mortality (HR: $0.44,95 \%$ CI: 0.23-0.82) and for 'start at less than 60 years' of health checks for mortalities from cancer (HR: 0.37 , 95\% CI: 0.190.71 ) and heart disease (HR: $0.40,95 \% \mathrm{CI}: 0.18-0.88$ ).

Table 4 shows the adjusted HRs for heart disease and stroke mortalities after excluding those who reported receiving treatment for the index disease at the enrollment of this study. Age of 85 years or more remained as an independent risk factor for mortality from heart disease. The adjusted HRs for appreciable and severe disabilities, 3.60 (95\% CI: 1.28-10.08) and 6.31 (95\% CI: 1.72-23.17), respectively, remained as independent risk factors for stroke mortality. 'Start at less than 60 years' of health checks achieved marginal statistical significance for

Table 3. Multivariate hazard ratios * for overall and cause-specific mortalities.

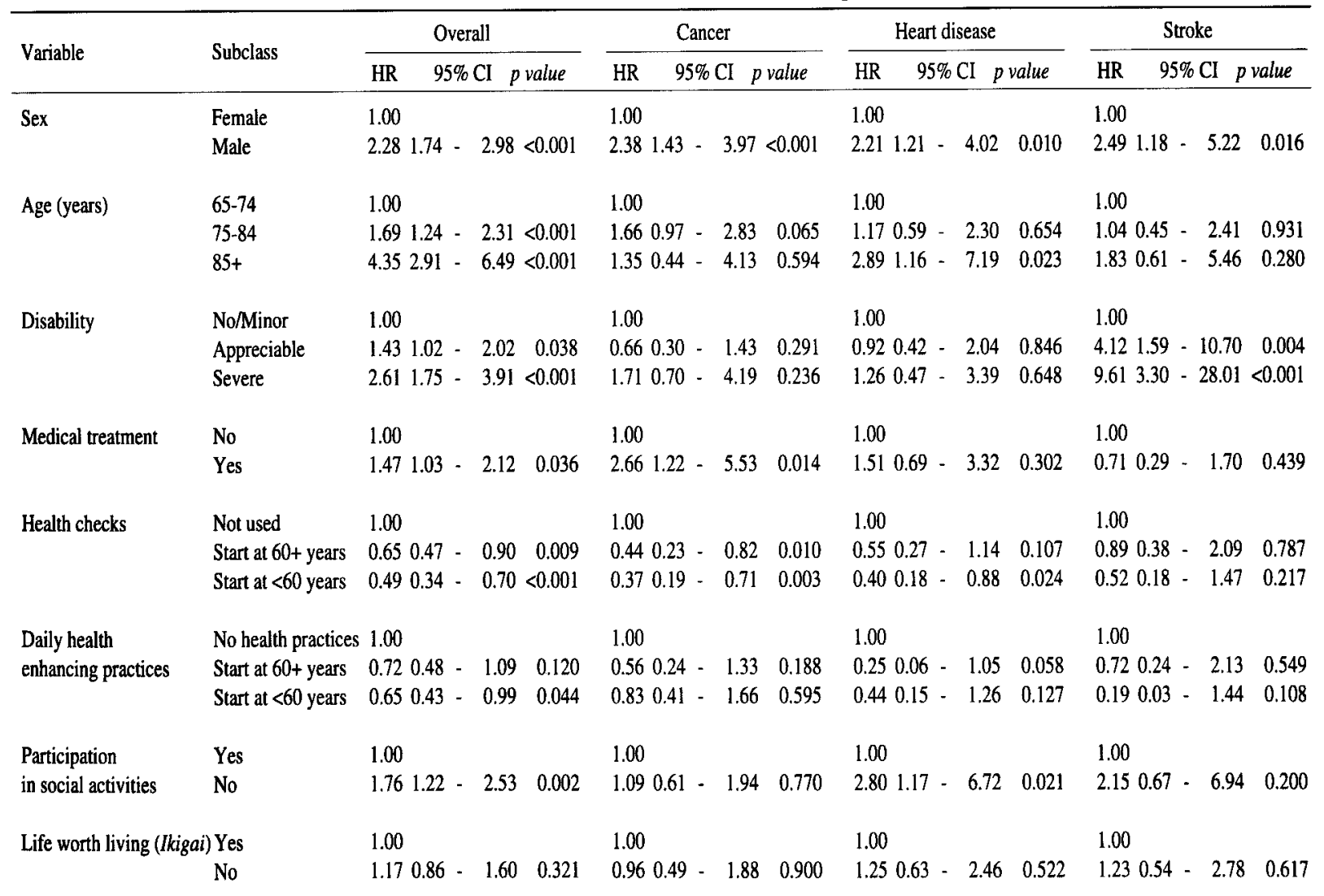

* HR: hazard ratio; $\mathrm{Cl}$ : confidence interval. 
Table 4. Multivariate hazard ratios * for heart disease and stroke mortalities among those who reported not having the index disease at the enrollment of this study.

\begin{tabular}{|c|c|c|c|c|c|c|c|c|c|c|c|}
\hline \multirow{3}{*}{$\begin{array}{l}\text { Variable } \\
\text { Sex }\end{array}$} & \multirow{3}{*}{$\begin{array}{l}\text { Subclass } \\
\text { Female }\end{array}$} & \multicolumn{5}{|c|}{ Heart disease } & \multicolumn{5}{|c|}{ Stroke } \\
\hline & & \multirow{2}{*}{$\begin{array}{r}\text { HR } \\
1.00\end{array}$} & \multicolumn{3}{|c|}{$95 \% \mathrm{CI}$} & $p$ value & \multirow{2}{*}{$\begin{array}{r}\text { HR } \\
1.00\end{array}$} & \multicolumn{3}{|c|}{$95 \% \mathrm{CI}$} & $p$ value \\
\hline & & & & & & & & & & & \\
\hline & Male & 1.93 & 0.98 & - & 3.77 & 0.056 & 2.05 & 0.86 & - & 4.92 & 0.107 \\
\hline \multirow[t]{3}{*}{ Age (years) } & $65-74$ & 1.00 & & & & & 1.00 & & & & \\
\hline & $75-84$ & 1.46 & 0.67 & - & 3.16 & 0.340 & 1.72 & 0.63 & - & 4.70 & 0.293 \\
\hline & $85+$ & 4.60 & 1.72 & - & 12.28 & 0.002 & 1.97 & 0.48 & - & 8.10 & 0.350 \\
\hline \multirow[t]{3}{*}{ Disability } & No/Minor & 1.00 & & & & & 1.00 & & & & \\
\hline & Appreciable & 0.71 & 0.28 & - & 1.82 & 0.475 & 3.60 & 1.28 & - & 10.08 & 0.015 \\
\hline & Severe & 1.16 & 0.39 & - & 3.46 & 0.788 & 6.31 & 1.72 & - & 23.17 & 0.006 \\
\hline \multirow[t]{2}{*}{ Medical treatment } & No & 1.00 & & & & & 1.00 & & & & \\
\hline & Yes & 1.50 & 0.66 & - & 3.38 & 0.330 & 0.56 & 0.22 & - & 1.40 & 0.213 \\
\hline \multirow[t]{3}{*}{ Health checks } & Not used & 1.00 & & & & & 1.00 & & & & \\
\hline & Start at $60+$ years & 0.52 & 0.23 & - & 1.17 & 0.113 & 1.06 & 0.41 & - & 2.77 & 0.904 \\
\hline & Start at $<60$ years & 0.41 & 0.17 & - & 1.01 & 0.052 & 0.33 & 0.08 & - & 1.33 & 0.120 \\
\hline \multirow{3}{*}{$\begin{array}{l}\text { Daily health } \\
\text { enhancing practices }\end{array}$} & No health practices & 1.00 & & & & & 1.00 & & & & \\
\hline & Start at $60+$ years & 0.34 & 0.08 & - & 1.45 & 0.146 & 1.06 & 0.34 & - & 3.26 & 0.922 \\
\hline & Start at $<60$ years & 0.53 & 0.18 & - & 1.55 & 0.245 & 0.30 & 0.04 & - & 2.34 & 0.252 \\
\hline \multirow{2}{*}{$\begin{array}{l}\text { Participation } \\
\text { in social activities }\end{array}$} & Yes & 1.00 & & & & & 1.00 & & & & \\
\hline & No & 2.14 & 0.86 & - & 5.31 & 0.102 & 1.63 & 0.48 & - & 5.50 & 0.434 \\
\hline \multirow[t]{2}{*}{ Life worth living (lkigai) } & Yes & 1.00 & & & & & 1.00 & & & & \\
\hline & No & 1.23 & 0.57 & - & 2.66 & 0.594 & 1.58 & 0.61 & - & 4.08 & 0.349 \\
\hline
\end{tabular}

* HR: hazard ratio; CI: confidence interval.

death from heart disease (HR: $0.41,95 \%$ CI: $0.17-1.01$, $\mathrm{p}=0.052$ ).

\section{DISCUSSION}

The independent associations between certain indicators and overall mortality among elderly people identified in this study are in agreement with the results of a number of epidemiological studies involving a variety of populations and methodologies ${ }^{1-8)}$. The strong predictive power of age, male sex, selfassessed health, degree of disability, satisfaction with life, social support, and sociability for overall mortality has been proven among elderly people. Our study also showed close relations between age, male sex, and poor health status as indicated by degree of disability and the risk of overall mortality. As for psychosocial conditions, no participation in social activities and the lack of specific meaningful aspects of life (no Ikigai) were strongly related to overall mortality of the elderly.
Our results provide some evidence that comparatively less decline in general health and stronger participation in social activities and identification of particular aspects of life as worth living for reflect an active physiological and psychological profile and a better adaptation to the environment and thus contribute to reducing the overall mortality of elderly people. In regard to health management, the positive relation between the whole spectrum of physical health and actual daily good health habits has been demonstrated ${ }^{10,14,15)}$, and use of health checks or screening is found to be related to reduction in overall mortality, length of hospitalization, and improvement in

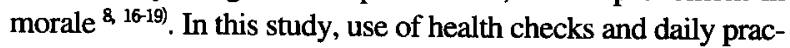
tices of health enhancing activities remained throughout as statistically significant factors associated with overall survival, and these tendencies were more pronounced among those who started their health checks or daily health enhancing practices before 59 years of age. These results suggest that positive behavioral patterns and an early start with health management 
and promotion may contribute to better health in old age and to reducing the overall mortality of the elderly.

As for cause-specific mortality, male sex was a constant risk factor for the three major causes of death, while advanced age and poor health status as indicated by disability were significantly associated with mortality from heart disease and stroke, respectively. Our finding of an association between poor health status and stroke mortality was consistent with that of a recent report on a 3-year follow-up of community-based elderly people in Japan ${ }^{20}$, which revealed that dependence in activities of daily living (ADL) was independently associated with stroke mortality. Furthermore, on the basis of a 7-year follow-up of noninstitutionalized elderly people in the state of Connecticut, USA, Colantonio et al. ${ }^{21)}$ reported that impairment of function was independently associated with stroke incidence and concluded that physical disability is an identified risk factor for stroke in elderly persons. These results indicate that in elderly persons, measurement of physical function may help to improve estimates of the probability of impending stroke as well as of stroke mortality. In regard to psychosocial conditions, no participation in social activities showed a strong association with mortality from heart disease. In this connection, Tsuji et al. ${ }^{200}$ reported that limited ambulatory ability was a significant predictor of mortality from heart disease. These results suggest that an active physiological profile or less decline in ADL may contribute to reducing the mortality from heart disease in the elderly.

As for medical treatment, undergoing medical treatment did not show a significant association with mortality from heart disease or stroke, but remained a significant risk factor for cancer mortality. Some of those enrolled in this study who died of cancer may have had cancer and been undergoing therapy, thus contributing to a predictive risk factor for cancer mortality. Furthermore, certain medications might lead to cancer and might be administered under conditions that are associated with immediate risk for cancer mortality. Further investigation of medication, for which neither of the databases used in this study provided information, may be needed to clarify whether medical treatment is merely associated with cancer mortality or actually contributes to or is responsible for cancer mortality.

In regard to preventive health measures, use of health checks and daily practices of health enhancing activities showed strong associations with the three major causes of death, and these tendencies were more pronounced among those who started health checks or daily health enhancing practices prior to 59 years of age. These results indicate that preventive health measures such as health checks or daily health enhancing activities may contribute to reducing the mortality from cancer and cardiovascular diseases, thus resulting in the reduction of overall mortality.

When examining the reasons for these results, the methodological limitations of the current study should be taken into consideration. First, only limited baseline data on disability, health management or psychosocial conditions and none on potential determinants such as morbidity, self-rated health or lifestyle were included. Second, we were unable to separate morbid from fatal events to determine the consistency, or lack thereof, of the relationship between observed associations and selected risk factors. Third, a secondary cause of death or complications were not considered in the calculation of risk for cause-specific mortality. Some of the association between the risk factors evaluated in this study and cause-specific mortality may be attributable to sequelae experienced by victims who subsequently die of another disease. Fourth, those who availed themselves of preventive health services showed a healthier status than those who did not as indicated by activities of daily living scores and disability scores. ${ }^{10,11}$ Furthermore, the percentages of those who took part in social activities or found life worth living (lkigai) were higher among those using health checks or practicing daily health enhancing activities than among those who were not. This type of self-selection bias shown by those availing themselves of preventive health services should be taken into account. Further investigations are also needed to clarify the theoretical causal mechanisms of specific associations with mortality.

Despite these potential limitations, our findings obtained from a cohort of community-residing elderly people support the concept that health status, undergoing medical treatment, and psychosocial conditions are related to specific causes of death. On the other hand, preventive health measures such as health checks or daily health enhancing practices may well represent predictive factors for reducing mortality related to the three major causes of death, thus resulting in a decrease in overall mortality among elderly people.

\section{ACKNOWLEDGMENT}

The authors would like to thank two referees for their helpful comments. This study was supported in part by Grand-in-Aid for Scientific Research (C) 08670426 from the Ministry of Education, Science, and Culture.

\section{REFERENCES}

1. Libow LS. Interaction of medical, biologic and behavioral factors on ageing adaptation and survival: an 11year longitudinal study. Geriatrics 1974;29:75-88.

2. Warren MD, Knight R. Mortality in relation to the functional capacities of people with disabilities living at home. J Epidemiol Community Health 1982;36:220-223.

3. Mossey JM, Shapiro E. Self-rated health: a predictor of mortality among the elderly. Am J Public Health 1982;72:800-809.

4. Berkman LF. Social networks, support and health: taking 
the next step forward. Am J Epidemiol 1986;123:559562.

5. House JS, Landis KR, Umberson D. Social relationships and health. Science 1988;241:540-545.

6. Grand A, Grosclaude P, Bocquet H, et al. Disability, psychosocial factors and mortality among the elderly in a rural French population. J Clin Epidemiol 1990;43:773782.

7. Sugisawa H, Liang J, Liu X. Social networks, social support, and mortality among older people in Japan. $\mathbf{J}$ Gerontol Soc Sci 1994;49:S3-13.

8. Nakanishi N, Tatara K, Takatorige T, Murakami S, Shinsho F. Effects of preventive health services on survival of the elderly living in a community in Osaka, Japan. J Epidemiol Community Health 1997;51:199-204.

9. Lentzner HR, Pamuk ER, Rhodenhiser EP, et al. The quality of life in the year before death. Am J Public Health 1992;82:1093-1098.

10. Nakanishi N, Tatara $K$, Takashima $Y$, et al. The association of health management with the health of elderly people. Age Ageing 1995;24:334-340.

11. Nakanishi N, Tatara K, Nakajima K, et al. Mortality in relation to disabilities, health management and psychosocial conditions among the community-residing elderly people. Jap J Public Health 1997;44:89-101 (in Japanese).

12. Martin J, Meltzer $\mathrm{H}$, Elliot $\mathrm{D}$. The prevalence of disability among adults. OPCS surveys of disability in Great Britain, Report 1. London: HMSO, 1988.

13. World Health Organization. International classification of diseases. Manual of the international statistical classification of diseases, injuries, and causes of death. Ninth Revision. Geneva: World Health Organization, 1977.

14. Belloc N, Breslow L. Relationship of physical health status and health practice. Prev Med 1972;1:409-421.

15. Breslow L. Prospects for improving health through reducing risk factors. Prev Med 1978;7:449-458.

16. Hendriksen C, Lund E, Stromgard E: Consequences of assessment and intervention among elderly people: a three year randomised controlled trial. Br Med J 1984;298:663-668.

17. Vetter NJ, Jones DA, Victor CR. Effects of health visitors working with elderly patients in general practice: a randomised controlled trial. Br Med J 1984;288:369-372.

18. Tulloch AJ, Moore V. A randomized controlled trial of geriatric screening and surveillance in general practice. $J$ R Coll Gen Pract 1979;29:733-742

19. McEwan RT, Davison N, Forster DP, et al. Screening elderly people in primary care: a randomized controlled trial. Br J Gen Pract 1990;40:94-97.

20. Tsuji I, Minami Y, Keyl PM, et al. The predictive power of self-rated health, activities of daily living, and ambulatory activity for cause-specific mortality among the elderly: a three-year follow-up in urban Japan. J Am Geriatr Soc 1994;42:153-156.

21. Colantonio A, Kasl SV, Ostfeld AM. Level of function predicts first stroke in the elderly. Stroke 1992;23:13551357.community. Stroke 1982;13:62-73. 